\title{
WILLIAM P. BARNETT E A EVOLUÇÃO DA COMPETIÇÃO: A TEORIA DA RED QUEEN
}

\section{RESUMO}

O livro "The Red Queen among organizations: how competitiveness evolves" sintetiza e estende diversos trabalhos nos quais William P. Barnett estuda a competição entre empresas, com base na ideia de que as organizações aprendem através do ato de competir e que, ao fazê-lo, se tornam competidores mais fortes ao longo do tempo. Uma resenha deste livro é aqui apresentada, sumarizando a teoria desenvolvida por Barnett e os testes empíricos que o autor realizou para o validação das suas hipóteses principais em duas indústrias, com resultados parcialmente confirmatórios. Em complemento à exposição da teoria e dos seus testes, são apresentados também os resultados de uma pesquisa bibliométrica realizada na base ISI Web of Science, que investiga o impacto da obra de Barnett e sua influência sobre diferentes linhas de pesquisa voltadas à competição entre empresas.

Palavras chaves: Estratégia Empresarial; Gerenciamento Estratégico; Competição; Ecologia Organizacional; Aprendizado Organizacional; Evolução Organizacional; Bibliometria.

\section{WILLIAN P. BARNETT AND COMPETITIVE EVOLUTION: A THEORY OF RED QUEEN}

\begin{abstract}
The book "The Red Queen among organizations: how competitiveness evolves" synthesizes and extends several works in which William P. Barnett studies competition among companies, based on the idea that organizations learn through the act of competing and, by doing so, they become stronger competitors over time. A review of this book is presented here, summarizing the theory developed by Barnett and the empirical tests that the author carried out for the validation of his main hypotheses in two industries, with partially confirmatory results. In addition to the exposition of theory and its tests, the results of a bibliometric research carried out at ISI Web of Science, which investigates the impact of Barnett's work and its influence on different lines of research aimed at competition amog companies are also presented.
\end{abstract}

Keywords: Business Strategy; Strategic Management; Competition; Organizational Ecology; Organizational Learning; Organizational Evolution; Bibliometry. 


\section{WILLIAM P. BARNETT Y LA EVOLUCIÓN DE LA COMPETICIÓN: LA TEORÍA DE LA RED QUEEN}

\section{RESUMEN}

El libro "The Red Queen entre organizaciones: cómo competitividad evolutiva" sintetiza y extiende diversos trabajos en los que William P. Barnett estudia la competencia entre empresas, sobre la base de la idea de que las organizaciones aprenden a través del acto de competir y que, se convierten en competidores más fuertes a lo largo del tiempo. Una reseña de este libro es presentada aquí, resumiendo la teoría desarrollada por Barnett y las pruebas empíricas que el autor realizó para la validación de sus hipótesis principales en dos industrias, con resultados parcialmente confirmatorios. En complemento a la exposición de la teoría y de sus pruebas, se presentan también los resultados de una investigación bibliométrica realizada en la base ISI Web of Science, que investiga el impacto de la obra de Barnett y su influencia sobre diferentes líneas de investigación dirigidas a la competencia entre empresas.

Palabras claves: Estrategia Empresarial; Gestión Estratégica; Competición; Ecología Organizacional; Aprendizaje Organizacional; Evolución Organizacional; Bibliometría.

Thiago de Luca Sant'ana Ribeiro ${ }^{1}$ José Eduardo Valladares Teixeira ${ }^{2}$

\footnotetext{
1 Mestrando em Administração pela Universidade Nove de julho - UNINOVE. Brasil. E-mail: thiago_delucka@hotmail.com

$\frac{1}{2}$ Mestrando em Administração pela Universidade Nove de julho - UNINOVE. Brasil. E-mail: j.e.teixeira@terra.com.br
} 


\section{INTRODUÇÃO}

No livro intitulado "The Red Queen among organizations: how competitiveness evolves" (TRQAO), Barnett apresenta sua contribuição para a explicação de uma das questões fundamentais da gestão estratégica: por que algumas organizações são mais bem sucedidas que outras (Derfus, Maggitti, Grimm, \& Smith, 2008)? Diversas correntes teóricas têm procurado endereça-la, como a da organização industrial (Bain, 1968; Porter, 1980), a economia evolucionária (Nelson \& Winter, 1982), a teoria das redes de relacionamento ou das redes sociais (Granovetter, 1985; Dyer \& Singh, 1998), a teoria da aprendizagem organizacional (Levitt \& March, 1988) e a visão de recursos (Wernenfelt, 1984; Barney, 1991), em suas diversas variantes e extensões, como a perspectiva das capacidades dinâmicas (Teece, Pisano, \& Shuen, 1997).

William P. Barnett se dedicou, nas duas décadas que precederam a publicação de TRQAO em 2008, ao estudo dos processos de competição entre populações de empresas, tendo como referencial teórico principal a ecologia organizacional (Hannan \& Freeman, 1977; Carroll, 1984; Singh \& Lumsden, 1990; Amburgey \& Rao, 1996, Carroll \& Barnett, 2004). A teoria de competição proposta pelo autor é ecológica -ao enfrentar concorrentes no mercado, as empresas não conseguem alcançar o nível de desempenho possível numa situação de monopólio ou de ausência de competição. Num ambiente competitivo, as empresas procuram melhorar seu desempenho experimentando alternativas para seu modelo de negócio e introduzindo inovações. Se algumas dessas tentativas resultam promissoras, a organização pode, através de um processo de disseminanção do apresendizado nelas alcançado, promover aperfeiçoamentos na sua estratégia e operações que levam sua competividade a patamares superiores. A sua maior competitividade força seus concorrentes a também experimentar e aprender, o que também os torna mais competitivos. Esses movimentos criam um ciclo contínuo de aumento da competitividade entre firmas numa mesma indústria. $\mathrm{O}$ aumento do nível de competividade geral diminui a viabilidade de cada uma das empresas individualmente, o que ser reflete, ao longo do tempo, em menores taxas de entrada de novos concorrentes e maiores taxas de saída (ou de mortalidade) de empresas que já atuam na indústria.

De acordo com a teoria proposta por Barnett, embora as empresas estejam continuamente melhorando para alcançar uma posição competitiva superior frente à concorrência, o processo não permite que uma vantagem momentânea seja mantida, uma vez que dispara uma busca similar por melhoria nos seus competidores, que os leva eventualmente a eliminar a vantagem original da empresa e, em muitos casos, a ultrapassa-la. A energia dispendida não permite à empresa superar (de forma sustentada) a concorrência, criando a impressão de que ela está na verdade parada, no longo prazo. O nome dado a essa teoria, Red Queen, é uma alusão a uma passagem do livro Through the Looking Glass, de Lewis Carroll, na qual Alice se surpreende com o fato dela e a da Rainha Vermelha (Red Queen) não saírem do mesmo lugar, após correrem em alta velocidade durante um bom tempo (Lewis Carroll, 1982, pp. 195-196):

"Well, in our country," said Alice, still panting a little, "you'd generally get to somewhere else - if you run very fast for a long time, as we've been doing."

"A slow sort of country!" said the Queen. "Now, here, you see, it takes all the running you can do, to keep in the same place."

Os estudos que identificam o efeito Red Queen na interação dinâmica e co-evolução mútua de entidades num determinado nicho ecológico surgem com o biologista van Valen (1973). Van Valen utilizou pela primeira vez esse nome, extraído do livro de Lewis Carroll, para descrever o processo no qual participantes de um sistema dinâmico desenvolvem, em ritmo crescente, atividades com o objetivo de manter sua competividade relativa (Derfus et al., 2008). Posteriormente, Red Queen foi utilizado como suporte ao desenvolvimento de teorias para explicação de comportamento de entidades em vários contextos, como a biologia evolucionária (Marrow, Law \& Cannings, 1992), corrida armamentista (Baumol, 2004), aprendizado organizacional e cognição distribuida (Glazebrook \& Wallace, 2009), estratégia de operações (Su, Linderman, Schroeder, \& Van de Vem, 2014), e competição entre empresas, como no caso dos trabalhos de Barnett (a partir de Barnett \& Hansen, 1996).

Esta resenha inclui, além desta introdução, quatro seções adicionais. Na seção 2 são apresentados maiores detalhes da teoria proposta por Barnett em TRQAO. A seção 3 apresenta um sumário dos testes empíricos que o autor realizou para o validação das suas hipóteses principais. A seção 4 detalha o método e os resultados da pesquisa bibliométrica sobre as citações da obra de Barnett com foco na teoria da Red Queen. A seção 5 final apresenta considerações sobre os resultados obtidos na pesquisa bibliométrica realizada e contextualiza a importância da contribuição de Barnett e da teoria da Red Queen sobre a investigação científica voltada à competição entre empresas.

\section{A TEORIA DA RED QUEEN}

\subsection{Conceitos principais}

No Capítulo 1 de TRQAO Barnett declara o objetivo de ultrapassar o entendimento básico da competição Red Queen, transmitido pela citação à passagem do livro de Lewis Carroll, por meio do 
desenvolvimento rigoroso de uma teoria e de hipóteses testáveis. O primeiro passo adotado pelo autor é conceituar a competição Red Queen não como uma propriedade de mercados, mas como uma propriedade das organizações - que apresentam níveis de competitividade variados, mesmo numa mesma indústria, em função da sua história e experiência competitiva prévia.

As organizações são definidas pelo autor como sistemas intencionalmente racionais $\mathrm{e}$ adaptativos. As organizações dispõem não só de rotinas desenvolvidas para resposta a problemas atuais, mas também tendem a responder a problemas e oportunidades através de um esfoço planejado para melhorar sua situação. Seus membros procuram garantir à organização um nível de desempenho considerado satisfatório, de acordo com as suas aspirações; quando o desempenho cai abaixo desse nível, eles atuam para tentar restabelecê-lo, iniciando o que Cyert e March (1963) denominaram pesquisa problemística (problemistic search). Como os membros da organização têm um conhecimento limitado das razões pelas quais as organizações alcançam determinados níveis de desempenho e das consequências de suas ações atuais sobre o desempenho futuro, o aprendizado é alcançado pela experiência, um processo sujeito a erros e interpretações falhas (Barnett, 2008, pp. 4-5). Mais especificamente, como essa busca de melhorias geralmente é realizada somente quando o desempenho cai abaixo de um nível considerado adequado (estabelecido com base nas aspirações da organização), ela normalmente se encerra quando uma solução é encontrada para restabelecê-lo. E como toda busca de melhoria demanda esforço e implica custos e riscos, ela geralmente é realizada de forma sequencial e localizada - priorizando as soluções conhecidas e de melhor impacto, ao menos inicialmente. Somente se as soluções conhecidas falharem na solução das deficiências de desempenho é que a organização promoverá uma busca mais ampla de alternativas para melhoria, que, novamente, será encerrada assim que for possível restabelecer o nível de desempenho considerado aceitável.

O resultado acumulado da busca de soluções para deficiências de desempenho é um processo de aprendizado ao longo do tempo, que acrescenta novas competências e habilidades e que pode promover, de forma adaptativa, a melhoria na competitividade da organização. Como nem todas as organizações têm sucesso nas suas experiências voltadas para aumento da sua competitividade, um processo seletivo elimina do mercado aquelas que ficam para trás. Na teoria de Barnett, adaptação e seleção atuam de forma integrada, assegurando que somente as organizações que aprenderam e se adaptaram de forma bem sucedida a um quadro de competição progressivamente aumentada sobrevivem.
A teoria proposta por Barnett também assume, com base em conceitos da ecologia organizacional, que os ambientes organizacionais são caracterizados por recursos limitados, e que as organizações num determinado ambiente ou nicho competem pelos mesmos recursos - em outras palavras, a competição é orientada pela escassez, num jogo de "soma zero", no qual os ganhos de uma empresa representam perdas para uma ou mais empresas. A competição por recursos num dado ambiente é intensificada quando as organizações são similares, uma vez que essa similaridade aumenta a dependência de recursos comuns (Barnett, 2008, p. 7). Dessa forma, num ambiente de competição Red Queen, o processo de aprendizado de uma organização resultante da busca de soluções para seus déficts de desempenho levam à sua maior competitividade, que por sua vez afeta (negativamente) a competitividade dos seus concorrentes. Nesse processo, toda a ação implementada por uma organização causa um desequilíbrio, que dispara ações de melhoria nos seus concorrentes, num processo que em última instância tende a alcançar todas as organizações num mesmo ambiente ou nicho ecológico, mesmo quando essas empresas não se consideram concorrentes diretos.

Segundo Barnett, as regras e a natureza da competição variam de forma significativa em diferentes contextos. Em consequência, o sucesso decorre não da adoção de uma melhor estratégia, mas da estratégia mais bem adaptada ao que Barnett chama da "lógica de competição" predominante num dado mercado. A lógica de competição é definida como "um sistema de princípios num determinado contexto que determina quem pode competir, como competem, quais critérios determinam sucesso ou fracasso e quais as consequências do sucesso ou fracasso" (Barnett, 2008, p. 9). Os princípios de uma determinada lógica de competição podem ser formais (como, por exemplo, políticas governamentais que determinem a obrigatoriedade de licenças ou autorizações) ou informais (como práticas consideradas obrigatórias por clientes e fornecedores para estabelecimento de relações com possíveis parceiros de negócio num determinado mercado).

O entendimento de como a competição Red Queen opera num determinado contexto ou mercado exige entender a lógica de competição nele dominante. É a lógica de competição que determina, em larga medida, quais recursos, competências ou capacidades são mais valiosos e que garantem diferenciais de desempenho entre as organizações que atuam num dado mercado. Da mesma forma que a racionalidade limitada nas organizações as impede de compreender completamente os antecedentes de níveis diferenciados de desempenho, a lógica de competição num dado mercado muitas vezes é ambígua, por depender de aspectos incertos da tecnologia, arquitetura organizacional e ambiente institucional. A lógica de competição não pode ser perfeitamente conhecida por 
uma organização que não atua num mercado: ela é identificada através da experiência da competição, que permite inferir (mesmo que de forma parcial, dadas as ambiguidades envolvidas) quais as estratégias vencedoras e quais as que não resultam em sucesso. A teoria proposta por Barnett incorpora o conceito de lógicas de competição, preconizando que o efeito do aprendizado de uma empresa coevoluindo num dado contexto espacial ou temporal pode ter consequências distintas das que seriam observados em outros contextos.

Embora a competição Red Queen seja a tônica em diversos mercados, muitas empresas buscam evitala. Alguns dos meios utilizados são a realização de fusões e aquisições, que autor denomina "lógica da predação", e o estabelecimento de cartéis e acordos. Para Barnett, essas estratégias podem minimizar ou retardar os efeitos da competição Red Queen, mas, ao mesmo tempo, eliminam os efeitos positivos do aprendizado que as organizações obtém do embate com seus concorrentes e, em última análise, dos benefícios econômicos decorrentes do processo de aprendizado, adaptação e seleção das empresas para a sociedade como um todo, que remete ao conceito Schumpteriano de destruição criativa (Schumpeter, 1942).

Ainda quanto à lógica de competição, Barnett defende que as organizações muitas vezes atuam em mercados submetidos a lógicas de competição conflitantes. Diferentes segmentos de um mesmo mercado de produtos podem ser orientados por lógicas de competição distintas: Barnett cita como exemplo o mercado de cervejas, no qual o segmento das cervejas artesanais é dominado pela lógica de autenticidade e raridade, ao invés da consistência de qualidade e as competências de marketing e distribuição, que dominam a lógica de competição para as cervejas produzidas em larga escala. Para o autor, a competição entre lógicas de competição alternativas pode ser considerada uma "meta-competição", que determina, a longo prazo, qual a lógica que prevalecerá num determinado mercado e, em consequência, quais as empresas nele serão mais competitivas e sobreviverão.

A análise da lógica de competição é dificultada, além das ambiguidades citadas anteriormente, também pelo fato estarem em contínua evolução em diferentes contextos espaciais e temporais. A evolução da tecnologia empregada num dado mercado, por exemplo, pode levar a alterações significativas na lógica de competição dominante e, por consequência, ao sucesso ou fracasso de empresas específicas.

\subsection{Hipóteses}

No capítulo 3 de TRQAO, Barnett apresenta as cinco hipóteses decorrentes dos conceitos da teoria da competição Red Queen expostos anteriormente nos capítulos 1,2 e 3 . A primeira delas é a chamada hipótese da histerese competitiva (competitive hysteresis hypothesis), que propõe que organizações com maior exposição a uma história recente de competição são mais viáveis e geram uma competição mais intensa, no contexto de uma determinada lógica de competição. A maior viabilidade dessas empresas é explicada pelo desenvolvimento de um leque maior de competências por conta do seu aprendizado, necessário para enfrentar os desafios da concorrência ao longo do tempo. Em consequência do efeito que a empresa mais competitiva exerce sobre os recursos disponíveis para as demais organizações que coabitam seu nicho ecológico, essa empresa gera uma competição mais intensa no seu ambiente de atuação.

As experiências recentes têm, na visão do autor, uma relevância maior do que experiências no passado distante. As empresas perdem parte da sua memória à medida em que o tempo passa e as pessoas que são o repositório dessas experiências as deixam. Em consequência, as lições aprendidas há muito tempo se tornam pouco acessíveis ou até mesmo se distorcem. As organizações muitas vezes continuam a operar como se os processos, estruturas e rotinas institucionalizados como resposta a desafios do passado se mantém válidos, o que prejudica sua adaptação à lógica de competição dominante no presente, especialmente se essa lógica se modificou ao longo do tempo. Num ambiente de competição Red Queen, Barnett considera ainda que o efeito de inadequação do aprendizado do passado remoto aos desafios do presente se intensifica, devido à sua natureza coletiva: como na competição Red Queen as empresas imitam (aprendem com) as outras, populações inteiras podem adotar os mesmos comportamentos baseados no passado distante que não são mais adequados aos desafios do presente. Esse argumento é a base para a segunda hipótese proposta por Barnett, denominada hipótese da armadilha da competência (competency-trap hypothesis): organizações com maior exposição a competição no passado distante são menos viáveis e geram competição mais fraca.

A terceira hipótese proposta pelo autor é a hipótese da adaptação custosa (costly adaptation hypothesis): para um determinado patamar de competição, a viabilidade de uma organização cai com o número de rivais que enfrentou. Essa hipótese tem como base a ideia de que num processo de competição Red Queen a busca e a implementação de mudanças numa organização envolve custos de diversas naturezas, como, por exemplo, custos de desenvolvimento de novos produtos e serviços, implementação das rotinas para sua produção e de novas estruturas organizacionais. Esses custos aumentam em função do número de rivais enfrentados pela organização e da necessidade de adaptação aos distintos desafios por eles representados. Quando uma organização tenta se adaptar simultaneamente aos desafios competitivos associados a um número elevado de rivais, pode, em certos casos, terminar numa posição competitiva em que é incapaz a responder 
adequadamente aos desafios oferecidos por cada um dos concorrentes - jack of all trades, master of none.

Para o aprendizado ser adaptativo, Barnett defende que as lições acumuladas devem representar adequadamente a lógica de competição prevalente. Em muitos casos, contudo, as experiências vivenciadas pelas empresas são limitadas e marcadas por vieses, levando a uma miopia no aprendizado organizacional, que dificulta a compreensão adequada da lógica de competição e, em consequência, a concepção e implementação de ações que aumentem sua competitividade no ambiente em que atua. Quanto menor o número de rivais com os quais a organização compete ao longo do tempo, ou quanto menos diferenciados esses rivais, mais provável que as experiências vivenciadas nessa competição gerem um aprendizado míope. A quarta hipótese proposta por Barnett é denominada hipótese do aprendizado míope (myopic learning hypothesis): quanto maior a dispersão da exposição histórica à concorrência, mais viável a organização.

Em muitas situações, as organizações respondem à concorrência não através do aprendizado e da melhoria, mas via aquisição ou fusão com rivais. Essas estratégias, descritas por Barnett como predatórias, removem as condições que dão origem à competição Red Queen e proporcionam ganhos de escala às empresas que as adotam e as beneficiam com retornos superiores, devido à ausência de competição. Porém a menor competição proporciona menor estímulo para o aprendizado e para a melhoria da sua competitividade. Se as vantagens da escala e da menor competição forem desconsideradas, Barnett defende que os efeitos de uma estratégia predatória são prejudiciais para a viabilidade das organizações. Essa é a base para a quinta e última das hipóteses propostas, a da predação custosa (costly predation hypothesis): se forem eliminados os efeitos de escala e da menor competição, a viabilidade da organização cai com o número de rivais históricos distintos que adquiriu.

\section{TESTES EMPÍRICOS DA TEORIA}

O teste empírico da teoria da competição Red Queen é apresentado nos capítulos 5 e 6 de TRQAO, que mostram, respectivamente, sua aplicação no contexto de bancos comerciais no estado de Illinois, Estados Unidos da América, e de fabricantes norteamericanos de computadores. O teste é realizado através de modelos (esses descritos no capítulo 4) para fundação e encerramento de operações das organizações que competem nesses mercados.

\subsection{Bancos comerciais no estado de Illinois}

Barnett justifica a escolha do mercado bancário de Illinois para a análise da competição Red Queen com base nas características particulares do ambiente regulatório daquele estado, que proibiu durante boa parte do século XX a constituição de redes de agências da mesma instituição financeira abarcando múltiplos condados. Esse modelo regulatório levou à prevalência de bancos comerciais de uma única agência, gerando uma amostra para análise constituída por uma massa de centenas de organizações em mercados locais independentes. Segundo o autor, essa regulação contrária às instituições bancárias multiagência ao mesmo tempo que impediu o domínio do mercado estadual pelos bancos nacionais, também ajudou os bancos locais a consolidarem seu poder muitas cidades de pequeno porte do estado de Illinois foram servidas por somente um banco durante muitos anos no período da pesquisa. A regulação vigente durante boa parte do período coberto pela pesquisa, que vai de 1900 a 1993, também restringia a oferta de serviços dos bancos comerciais e os preços que podiam ser praticados, limitando a capacidade de diferenciação das instituições financeiras. A crise financeira do final dos anos 1920 e início dos anos 1930 levou, entre outros aperfeiçoamentos da regulação bancária nos EUA, à introdução do seguro depósito e ao aumento da supervisão estatal, que tiveram como consequências a redução na incidência de crises de confiança no sistema financeiro, o estímulo à estabilização do mercado bancário (mesmo que à custa de menor competição) e a redução substancial nas taxas de fundação e de encerramento de operações dos bancos comerciais no país. A combinação desses fatores levou a um cenário de competição apenas moderada entre os bancos comerciais no estado de Illinois, que se manteve durante o período da pesquisa, dominada por duas lógicas de competição rivais: a da eficiência fiduciária (quão bem as organizações operavam como bancos) e a do poder institucional ou predação (aquisição de rivais para a obtenção de uma posição de mercado monopolista e, em decorrência dela, para proteção contra os efeitos negativos de uma competição local intensa sobre os resultados).

Os dados coletados dos bancos comerciais de Illinois e sua análise estatística suportam de forma parcial as hipóteses da competição Red Queen propostas por Barnett, conforme apresentado na Tabela 1, reproduzida da resenha de TRQAO de Swaminathan (2009). As predições básicas do modelo da competição Red Queen foram suportadas; em particular, a fundação e o encerramento de operações de bancos comerciais estão fortemente associados à hipótese da histerese competitiva: a viabilidade e competitividade dessas instituições financeiras depende de se experimentaram competição em sua história.

\subsection{Fabricantes de computadores nos Estados Unidos da América}

Barnett focaliza no capítulo 6 de TRQAO o teste empírico da teoria da competição Red Queen na indústria de computadores nos Estados Unidos da 
América, contemplando as organizações daquele país que fabricavam, vendiam, alugavam ou arrendavam computadores digitais de uso geral, no período entre 1951 e 1994. O autor divide a indústria em três segmentos, nos quais conduz sua análise e testa as hipóteses do seu modelo: mainframes, minicomputadores e microcomputadores.

$\mathrm{O}$ segmento de mainframes é o primeiro a surgir, ainda em 1951, com os primeiros equipamentos voltados para o uso geral, inicialmente empregados para o uso científico ou em grandes corporações, por clientes que detinham um conhecimento avançado da tecnologia e pouco sensíveis a preço. Com o passar do tempo, os mainframes foram progressivamente ampliando sua aplicabilidade e penetração em organizações de porte progressivamente menor, por usuários também menos sofisticados. De uma ênfase inicial na introdução de inovação e solução de problemas técnicos via integração vertical, a lógica de competição nesse mercado passou a incorporar, à medida em que ele evoluía, atributos de serviço como suporte técnico e a utilização de componentes padronizados, providos por terceiros. Essa rápida evolução da lógica de competição dominante levou um processo de seleção e adaptação também acelerado, que resultou numa grande variação no número de empresas nelas competindo, ao longo dos anos.

O segmento de minicomputadores surge no início da década de 1960, com equipamentos que se diferenciam dos computadores de grande porte da época com uma combinação de tamanho e preços reduzidos e relação preço $\mathrm{x}$ desempenho superior, para tarefas computacionais específicas. Barnett visualiza o surgimento desse segmento como um movimento social, cujos participantes se vêm defensores de um modelo de computação no qual componentes de hardware e software de diversas fontes são integrados em equipamentos poderosos, porém acessíveis, em oposição às arquiteturas fechadas, proprietárias e caras dos mainframes então dominantes. As empresas que deram início ao segmento orientavam suas ofertas para usuários com conhecimento avançado de tecnologia, que portanto prescindiam de um nível de serviço de vendas e suporte técnico elevados. A arquitetura aberta dos minicomputadores permitia a seus usuários modifica-los, através da combinação de componentes de outros fabricantes, adaptando-os às suas necessidades específicas, explorando principalmente sua conectividade em rede. A lógica da competição nesse segmento emergiu da experiência das empresas que o iniciaram, descobrindo as demandas de seus clientes e aprendendo através da competição com seus concorrentes, num processo que criou novos nichos, como as estações de trabalho e os sistemas baseados em arquiteturas cliente-servidor.

O terceiro segmento identificado por Barnett é o dos microcomputadores, surgido por volta de 1973.
O surgimento desse tipo de equipamento é estreitamente ligado ao desenvolvimento dos microprocessadores, que simplificaram o projeto e a montagem de computadores pessoais, que se tornaram acessíveis a pessoas com conhecimentos técnicos limitados. Inicialmente considerados equipamentos de uso pessoal voltados para amadores, os microcomputadores iniciaram uma revolução na indústria da computação, liderada por alguns visionários que, através de processo de descoberta, evolução tecnológica e de marketing tornariam em poucos anos um hobby num mercado de massa, com sua própria lógica de competição. Essa lógica contemplava, inicialmente, a entrega de produtos de baixo custo, fáceis de usar, antes dos concorrentes, usando componentes disponíveis ("de prateleira"). Com o passar do tempo, a competição passa a se dar de acordo com algumas arquiteturas e sistemas operacionais padrões de facto. Segundo Barnett, esses padrões emergem da concorrência entre rivais na indústria, como resposta a pressões competitivas e sem serem orientados por uma estratégia pré-definida e bem calculada. O surgimento do padrão Wintel acirrou a competição entre os fabricantes de microcomputadores, acelerando o lançamento de produtos com novas tecnologias e desempenho aumentado e proporcionou inovações na montagem e distribuição de equipamentos. Nesse processo, um número muito elevado de empresas se lançou no segmento de microcomputadores, com um número também elevado delas o abandonando.

Também no caso da indústria de computadores norteamericana, as evidências empíricas suportam parcialmente a teoria proposta por Barnett, conforme sumarizado na Tabela 1. O suporte mais forte é encontrado para a hipótese da histerese competitiva nos 3 segmentos de mercado considerados, os fabricantes com maior exposição à competição são os que apresentam maior probabilidade de sobrevivência e que geram a competição mais forte, reduzindo a taxa de fundação de novos entrantes no mercado. A hipótese da armadilha da competência encontrou suporte somente no segmento de mainframes, possivelmente por que os demais segmentos são mais recentes e neles o efeito do aprendizado realizado num passado remoto ainda não podiam ser observados. A hipótese da adaptação custosa também só foi suportada pela evidência empírica no segmento dos microcomputadores, segmento no qual, conforme o autor, seus efeitos podem ser observados mais facilmente, pela grande quantidade de empresas atuantes. A hipótese do aprendizado míope encontra o menor nível de suporte na evidência empírica: seus efeitos são observados somente nos modelos de fundação de empresas no segmento de mainframes. 
Tabela 1- Testes empíricos da teoria da competição Red Queen

\begin{tabular}{|c|c|c|c|c|c|}
\hline \multirow[b]{2}{*}{ Hipótese } & \multicolumn{5}{|c|}{ Taxa de Fundação } \\
\hline & Efeito previsto & Bancos em Illinois & Mainframes & Minicomputadores & Microcomputadores \\
\hline Histerese competitiva & Negativo & Negativo & Negativo & Não significativo & Negativo \\
\hline Armadilha da competência & Positivo & Positivo & Positivo & Não significativo & Não significativo \\
\hline Adaptação custosa & Positivo & Negativo & Negativo & Não significativo & Não significativo \\
\hline $\begin{array}{l}\text { Aprendizado míope (desigualdade na rivalidade } \\
\text { enfrentada pela organização ao longo do tempo) }\end{array}$ & Positivo & Negativo & Negativo & Não significativo & Não significativo \\
\hline $\begin{array}{l}\text { Aprendizado míope (desigualdade nos grupos de } \\
\text { rivais enfrentados pela organização no passado) }\end{array}$ & Positivo & Negativo & Não significativo & Não significativo & Positivo \\
\hline \multirow[t]{2}{*}{ Predação custosa } & Positivo & Positivo & & & \\
\hline & \multicolumn{5}{|c|}{ Taxa de Encerramento de Operações } \\
\hline Hipótese & Efeito previsto & Bancos em Illinois & Mainframes & Minicomputadores & Microcomputadores \\
\hline Histerese competitiva & Negativo & Negativo & Negativo & Não significativo & Negativo \\
\hline Armadilha da competência & Positivo & Negativo & Positivo & Não significativo & Não significativo \\
\hline Adaptação custosa & Positivo & Não significativo & Não significativo & Não significativo & Positivo \\
\hline $\begin{array}{l}\text { Aprendizado míope (desigualdade na rivalidade } \\
\text { enfrentada pela organização ao longo do tempo) }\end{array}$ & Positivo & Negativo & Não significativo & Não significativo & Não significativo \\
\hline $\begin{array}{l}\text { Aprendizado míope (desigualdade nos grupos de } \\
\text { rivais enfrentados pela organização no passado) }\end{array}$ & Positivo & Não significativo & Não significativo & Positivo & Não significativo \\
\hline Predação custosa & Positivo & Positivo & & & \\
\hline
\end{tabular}

Fonte: Adaptado de Swaminathan, 2009, p.691.

\subsection{Resultados gerais dos testes empíricos da teoria da competição Red Queen}

De forma geral, a hipótese da histerese competitiva encontra o maior nível de suporte nos testes empíricos realizados por Barnett para validação da teoria da Red Queen. Em contrapartida, a hipótese da aprendizado míope recebe pouco ou nenhum suporte. O teste realizado, restrito ao contexto dos bancos comerciais de Illinois, suporta a hipótese da predação custosa. As evidências apresentam resultados mistos, com relação à hipótese da armadilha da competência: por exemplo, a experiência dos incumbentes com a concorrência no passado distante aumenta a taxa de fundação de novos bancos no estado de Illinois, suportando a hipótese, embora esse efeito não tenha se manifestado no encerramento das operações dos bancos.

\section{A RELEVÂNCIA DA RED QUEEN PARA AS PESQUISAS}

Uma série de técnicas bibliométricas foram utilizadas de modo a possibilitar a mensuração do impacto da Red Queen nos principais campos de pesquisa relacionados. A bibliometria se utiliza de métodos matemáticos e estatísticos para medir a ciência, os cientistas e as atividades científicas de determinado domínio (Broadus, 1987). Garfield (1979) destaca que a bibliometria introduz uma medida de objetividade na avaliação da literatura científica, diminuindo assim o subjetivismo.

Os métodos bibliométricos têm dois usos principais: análise de desempenho e mapeamento de ciências (Cobo, López-Herrera, Herrera-Viedma, \& Herrera, 2011). Análise de desempenho procura avaliar o desempenho de pesquisa e publicação de indivíduos e instituições. O mapeamento da ciência visa revelar a estrutura e a dinâmica dos campos científicos. A teia que se forma deste mapeamento ajuda o pesquisador a entender determinada linha de pesquisa. Em última análise, esses métodos têm como finalidade tornar o pesquisador um maior conhecedor do tema de pesquisa de interesse.

Para Zupic e Carter (2015), existem cinco principais técnicas para se fazer uma bibliometria: 1) análise de citação; 2) análise de co-citação; 3) acoplamento bibliográfico (pareamento); 4) análise de co-autoria, e 5) análise de co-palavras. Este trabalho utiliza as três primeiras técnicas. Na primeira delas, a maioria dos trabalhos bibliométricos lista em forma de ranking os principais artigos, autores ou periódicos citados dentro de uma amostra. Desta forma, a análise de citações baseia-se na frequência de contagem - isto significa dizer que, à medida que outros pesquisadores citam determinado trabalho, este passa a ser um grande influente nos rumos de determinada linha de pesquisa. A co-citação acontece quando um par de citações são usadas juntas por um mesmo autor. A análise destas 
citações acopladas, permite aos estudiosos construir medidas de similaridade entre documentos, autores ou revistas (McCain, 1990), formando grupos (clusters) e identificando a estrutura da ciência de determinado domínio (Small, 1973). O acoplamento bibliográfico (pareamento) difere da co-citação por usar o número de referências compartilhadas por dois documentos como uma medida de similaridade entre eles. Quanto mais as bibliografias de dois artigos se sobrepõem, mais forte é a sua conexão (Zupic, \& Carter, 2015).

A pesquisa bibliométrica realizada procurou investigar três questões relacionadas: a importância da teoria da Red Queen, ao longo do tempo; a relevância das contribuições de Barnett em campos de pesquisa aos quais a teoria da Red Queen pode ser associada; e o relacionamento entre a teoria da Red Queen e os os trabalhos de outros pesquisadores que a citam. Os métodos específicos e os resultados das investigações sobre essas três questões são apresentados nas seções a seguir

Buscamos identificar nessas investigações as citações à obra de Barnett limitadas somente às referências de artigos científicos publicados em revistas acadêmicas revisadas por pares, considerando que esses artigos representam, conforme Ramos-Rodríguez e Ruíz-Navarro (2004) o conhecimento certificado (certified knowledge), isto é, submetido à revisão crítica de pesquisadores do mesmo campo de conhecimento e que obteve sua aprovação para publicação. Esses artigos foram encontrados dentre aqueles indexados na base ISI Web of Science, serviço considerado a fonte mais frequentemente utilizada para obtenção de dados bibliográficos (Zupic \& Carter, 2015).

A utilização da base ISI Web of Science traz, contudo, uma limitação à essa investigação, especialmente da primeira e da terceira questões (respectivamente, importância da teoria da Red Queen, ao longo do tempo e relacionamento entre a teoria da Red Queen e os trabalhos de outros pesquisadores que a citam): a base indexa livros de forma ainda restrita. A TRQAO, obra objeto dessa resenha, não está nela indexada. A indexação de livros na ISI Web of Science passou a ser realizada somente a partir de 2011, contemplando livros eletrônicos e em papel publicados a partir de 2005, que estão contidos no Book Citation Index, também incluso na Web of Science Core Colletion, usualmente empregada para pesquisas bibliográficas e aqui também utilizada. Análises realizadas sobre o conteúdo da Book Citation Index, como as de Bar-Ilan (2010) e de Torres-Salinas, Robison-Garcia, Campanario e López-Cózar (2014) apontam para limitações no número de livros incorporados à base (de um pequeno número de editoras) e falhas no processo de recuperação de citações de livros e capítulos de livros, que apontam para resultados inferiores aos que deveriam ser reportados. De forma a resolver as limitações para uma pesquisa bibliográfica sobre citações com base no livro TRQAO, optamos por realizar essa pesquisa a partir do artigo publicado por Barnett em coautoria com Morten T. Hansen (1996), intitulado "The Red Queen in Organizational Evolution", no qual os autores lançam as bases da teoria da Red Queen, inclusive apresentando os resultados do seu teste empírico no contexto dos bancos no estado de Illinois. Embora reconhecendo que TRQAO contém extensões e aprofundamento da teoria, suas hipóteses, modelagem matemática e teste, frente ao conteúdo originalmente publicado em 1996, entendemos adequado utilizar o artigo original como base para uma pesquisa bibliográfica que busca identificar o impacto e relevância da teoria. Daqui em diante, quando esta resenha faz alusão à Red Queen, ela se refere ao artigo de Barnett e Hansen (1996) e não ao livro TRQAO (Barnett, 2008).

\subsection{A importância da Red Queen ao longo do tempo}

Esta resenha traz uma análise geral dos artigos que citaram a Red Queen, analisando as publicações por ano e revista. Assim como as análises posteriores de co-citação e de pareamento, o recorte feito para esta análise consiste em todos os artigos publicados em revistas indexadas na base ISI Web of Science que citaram a Red Queen, porém restritos àqueles categorizados como Management, Business ou Sociology.

No que se refere ao número de citações por ano, observa-se que a partir de 2006, o trabalho The Red Quen passou a ser citado mais de 10 vezes por ano. O ano de 2009, logo após o lançamento do livro TRQAO, contou com 15 citações, e o ano de 2016, 17, assumindo a posição de ano com maior número de citações. A Figura 1 traz os resultados de forma gráfica. Depreende-se desses números que a Red Queen continua se desenvolvendo, ainda que paulatinamente, na ciência da administração e áreas correlatas. 
Figura 1 - Red Queen: citações por ano

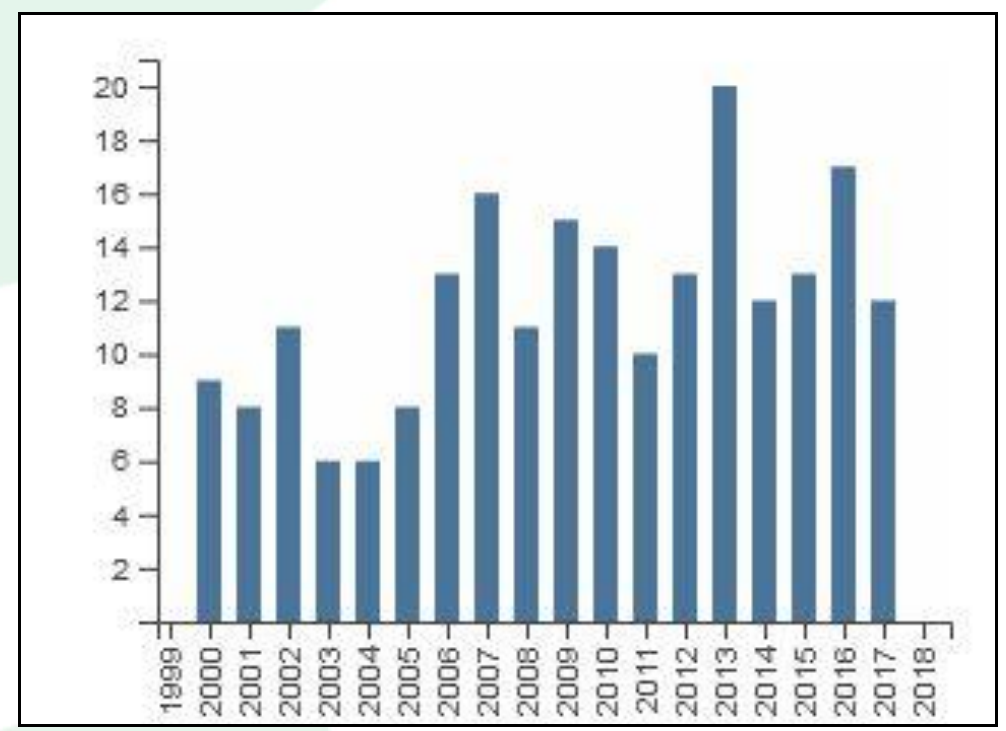

Fonte: ISI Web of Science

Outra análise feita foi em relação aos periódicos que receberam esses trabalhos. A Tabela 2 apresenta as 10 revistas com as maiores quantidades de registros.

Tabela 2 - Periódicos com mais trabalhos que citam a Red Queen

\begin{tabular}{|l|c|}
\hline \multicolumn{1}{|c|}{ Periódico } & $\mathbf{N}^{\mathbf{0}}$ de registros \\
\hline Strategic Management Journal & 19 \\
\hline Organization Science & 13 \\
\hline Advances In Strategic Management A Research Annual & 10 \\
\hline Academy Of Management Journal & 7 \\
\hline Management Science & 6 \\
\hline Industrial And Corporate Change & 5 \\
\hline Administrative Science Quarterly & 5 \\
\hline Academy Of Management Review & 5 \\
\hline Ecology And Strategy & 4 \\
\hline Academy Of Management Annals & 4 \\
\hline
\end{tabular}

Fonte: ISI Web Of Science

Percebe-se que uma grande área que vem explorando a Red Queen é a Gestão Estratégica, sendo representada no top 1 pela revista Strategic Management Journal, com 19 citações. Pode-se inferir também que journals do mais alto impacto abriram espaço para a Red Queen, como são os casos das revistas Academy of Management, Organizational Science e Administrative Science Quarterly, por exemplo.

\subsection{A relevância da contribuição de Barnett em diferentes campos de pesquisa}

$\mathrm{O}$ artigo "The Red Queen in Organizational Evolution", destacou entre as suas palavras-chaves os termos Strategic Management; Competition; Organizational Learning; Organizational Evolution; e Organizational Ecology. Nesta resenha, foram utilizados apenas os domínios Organizational Evolution, Organizational Learning e Organizational Ecology para identificar a expressividade do trabalho de Barnett. Competition e Strategic Management foram descartados por apresentarem características não específicas, ao contrário dos demais campos aqui selecionados. Em relação ao termo Organizational Learning, delimitou-se a busca aos anos 2014, 2015 e 
2016, pois existe uma grande quantidade de trabalhos neste campo e esses anos representam o período de maior publicação. Além desta restrição, foram considerados apenas artigos científicos categorizados como Management ou Business. Para os dois outros termos não houve delimitação temporal, mantendo-se apenas as restrições de categoria e de tipo de documento. Toda a busca ocorreu na ISI Web of Science.

\section{Análise de citações no campo Organizational Evolution}

Apesar de encontrados 1.316 artigos científicos neste campo, Barnett aparece apenas em duas posições dos 80 trabalhos mais citados da amostra. Seu trabalho com Carroll (1995) e seu trabalho Red Queen com Hansen (1996) aparecem nas $38^{\mathrm{a}}$ posição e $61^{\mathrm{a}}$ posição, respectivamente. Disso, denota-se que a expressividade do autor neste campo é moderada, apesar de ser o campo em que a Red Queen é mais citada. A Tabela 3 ilustra esta situação.

Tabela 3 - Principais trabalhos citados em Organizational Evolution

\begin{tabular}{|c|c|c|}
\hline Posição & Trabalho & N$^{\mathbf{o}}$ citações \\
\hline $1^{\mathbf{o}}$ & Nelson_Winter_1982 & 204 \\
\hline $2^{\mathbf{o}}$ & DiMaggio_Powell_1983 & 149 \\
\hline $3^{\mathbf{o}}$ & Hannan_Freeman_1984 & 143 \\
\hline $4^{\circ}$ & Hannan_Freeman_1989 & 137 \\
\hline $5^{\circ}$ & March_1991 & 120 \\
\hline $6^{\circ}$ & Eisenhardt_1989 & 114 \\
\hline $7^{\circ}$ & Cyert_March_1963 & 113 \\
\hline $8^{\circ}$ & Hannan_1977 & 113 \\
\hline $9^{\circ}$ & Teece_et_al_1997 & 109 \\
\hline $10^{\circ}$ & Cohen_Levinthal_1990 & 91 \\
\hline $38^{\circ}$ & Barnett_Carroll_1995 & 38 \\
\hline $61^{\circ}$ & Barnett_Hansen_1996 & 37 \\
\hline
\end{tabular}

Fonte: Elaborada pelos autores (2017)

O autor que aparece mais vezes entre os 10 trabalhos mais citados é Hannan, escrevendo sobre ecologia populacional (1977); publicando livro com Freeman sobre a ecologia organizacional propriamente dita (1989); e em outro trabalho com Freeman, discutindo questões relacionadas à inércia estrutural dentro da perspectiva de ecologia populacional (1984). O trabalho de Nelson e Winter (1982) diz respeito a uma teoria evolutiva da mudança econômica, e o seminal artigo de DiMaggio e Powell (1983) explora o conceito de isomorfismo dentro das organizações. Nesta lista ainda cabe destaque ao trabalho de March (1991), que elucida as diferenças entre exploration e exploitation dentro da aprendizagem organizacional.

\section{Análise de citações no campo Organizational Learning}

Foram identificados 1059 artigos no campo "Organizational Learning" entre os anos de 20142016, categorizados como Management e / ou Business. No entanto, desses mais de mil artigos, o trabalho Red Queen de Barnett (1996) aparece apenas na $4249^{a}$ posição, sendo este o seu trabalho mais citado neste domínio, e contando com apenas 3 citações. Depreende-se dessa informação, que o trabalho Red
Queen é praticamente inexpressivo neste campo de pesquisa. O trabalho mais citado é o de Cohen e Levinthal (1990) sobre capacidade absortiva - 178 citações, seguido por Podsakoff, MacKenzie e Lee (2003), que discutem os problemas de vieses nos métodos empregados nas pesquisas em ciências comportamentais - 169 citações. Completam o top 5 o trabalho de March (1991) - 163 citações, os trabalhos de Levinthal e March (1993) sobre miopia de aprendizado - 115 citações, e Fornell e Lacker (1981) acerca de métodos estatísticos - 111 citações. Os outros trabalhos que compõem o top 10 discutem especificamente aprendizagem organizacional, comportamento organizacional e conhecimento organizacional.

\section{Análise de citações no campo Organizational Ecology}

Este é certamente o campo de maior expressão para Barnett. Dentro de uma amostra de 360 artigos, Barnett aparece 6 vezes entre os 56 trabalhos mais citados. A Red Queen aparece justamente na posição 56, com 18 citações. Os quatro trabalhos mais citados da amostra são de Hannan e outros co-autores sobre ecologia organizacional. DiMaggio e Powell (1983) e 
Nelson e Winter (1982) são os $5^{\circ}$ e $6^{\circ}$ trabalhos da lista. A $7^{\text {a }}$ obra mais citada é o livro de Hannan e Carroll (1999), "The Demography of Corporation and Industries". Meyer e Rowan (1977) é o $8^{\circ}$ trabalho mais citado, abordando o assunto das regras institucionais e a questão da legitimidade. Stinchcombe (2000) sobre estruturas e organizações sociais e Carroll e Hannan (1989) sobre populações organizacionais completam a lista do top 10 , como o $9^{\circ}$ e o $10^{\circ}$ trabalhos mais citados respectivamente.

Em relação aos trabalhos de Barnett, o mais citado é o artigo feito em conjunto com Carroll (1987) em que discutem a competição e o mutualismo entre empresas de telefonia, dentro de uma perspectiva de ecologia organizacional. O segundo artigo mais citado é o trabalho individual de Barnett (1997) sobre a dinâmica da intensidade competitiva, em que explora e compara as características individuais que viabilizam uma organização com as características ecológicas propõe que nem sempre essas características caminham de mãos dadas. $\mathrm{O} 3^{\circ}$ trabalho discute sobre mudança organizacional e mais uma vez conta com Carroll (1995) na co-autoria. O $4^{\circ}$ trabalho aborda mais uma vez a questão das empresas telefônicas, porém dando um enfoque no assunto mortalidade organizacional. $\mathrm{O}$ artigo de Barnett e Amburgey (1990) no livro Organizational evolution: new directions é o $5^{\circ}$ mais citado, e a Red Queen (artigo de 1996) é o $6^{\circ}$. A Tabela 4 sintetiza os achados.

Tabela 4 - Os 6 trabalhos de Barnett mais citados em Organizational Ecology

\begin{tabular}{|c|c|c|}
\hline \multirow{2}{*}{ Posição } & Trabalho & No $^{\mathbf{0}}$ citações \\
\hline $13^{\circ}$ & Barnett_Carroll_1987 & 37 \\
\hline $24^{\circ}$ & Barnett_1997 & 26 \\
\hline $25^{\circ}$ & Barnett_Carroll_1995 & 26 \\
\hline $33^{\circ}$ & Barnett_1990 & 23 \\
\hline $45^{\circ}$ & Barnett_Amburgey_1990 & 24 \\
\hline $56^{\circ}$ & Barnett_Hansen_1996 & 18 \\
\hline
\end{tabular}

Fonte: Elaborada pelos autores (2017)

3.6 O relacionamento entre a teoria da $\operatorname{Red}$ Queen e os trabalhos de outros pesquisadores

O grupo de artigos que citou o trabalhode Barnett e Hansen (1996) também foi analisado, sendo feita uma análise de co-citação e uma análise de acoplamento bibliográfico (pareamento), buscando descobrir os principais clusters por trás desses artigos e o direcionamento que as pesquisas relacionadas à Red Queen estão a tomar.

Para as análises feitas nesta seção foram considerados 140 artigos. Chegou-se a este número ao serem identificados todos os trabalhos que citaram o artigo The Red Queen in Organizational Evolution, e feita a restrição por categoria, considerando apenas Business, Management e Sociology na base ISI WEB of Science.
The Red Queen in Organizational Evolution: análise de co-citação

A principal técnica utilizada nesta seção foi a análise fatorial exploratória. Procedimentalmente, adotou-se as recomendações de Hair et al. (2009), que sugerem a análise de KMO $(>0,5)$ como aceitável e superior a 0,8 como ótima. No que se refere às comunalidades, foi adotado como critério de aceitação os itens com valores maiores que 0,5. Para a classificação dos fatores, foram considerados apenas os itens com cargas fatoriais maiores que 0,5 e que simultaneamente não apresentassem cargas próximas em outros fatores - caso contrário, excluía-se o item e fazia-se uma nova rodada. Seguindo todos esses procedimentos e recomendações, chegou-se a um KMO de 0,849 , e a 3 fatores responsáveis pela explicação de $76,81 \%$ da variância total da amostra. Foram 46 trabalhos analisados. A tabela 5 apresenta os fatores. 
Tabela 5 - Análise fatorial exploratória dos artigos co-citados

\begin{tabular}{|c|c|c|c|}
\hline \multicolumn{4}{|c|}{ Matriz de componente rotativa ${ }^{a}$} \\
\hline & \multicolumn{3}{|c|}{ Componente } \\
\hline & 1 & 2 & 3 \\
\hline Barney_1991 & ,902 & & \\
\hline Penrose_1959 & 899 & & \\
\hline LeonardBarton_1992 & 886 & & \\
\hline Cohen_Levinthal_1990 &, 885 & & \\
\hline Levinthal_March_1993 & ,883 & & \\
\hline Stuart_Podolny_1996 &, 879 & & \\
\hline Brown_Eisenhardt_1997 & ,863 & & \\
\hline Porter_1991 & 854 & & \\
\hline Henderson_Clark_1990 & ,853 & & \\
\hline Levinthal_1997 & 844 & & \\
\hline Dierickx_Cool_1989 & ,837 & & \\
\hline Levitt_March_1988 &, 828 & & \\
\hline Cyert_March_1963 & ,816 & & \\
\hline Levinthal_March_1981 & ,801 & & \\
\hline Wernerfelt_1984 & ,792 & & \\
\hline Porter_1980 & ,784 & & \\
\hline March_Simon_1958 & ,774 & & \\
\hline Nelson_Winter_1982 & ,771 & & \\
\hline Haunschild_Miner_1997 & ,755 & & \\
\hline Schumpeter_1934 & ,753 & & \\
\hline March_1991 & ,731 & & \\
\hline Barnett_et_al_1994 & ,726 & & \\
\hline Baum_Singh_1994 & & ,892 & \\
\hline Podolny_et_al_1996 & & ,872 & \\
\hline Baum_Mezias_1992 & & ,865 & \\
\hline Zuckerman_1999 & & ,858 & \\
\hline Barron_West_1994 & & 848 & \\
\hline Carroll_Swaminathan_2000 & & 844 & \\
\hline Dobrev_et_al_2001 & & ,836 & \\
\hline Hannan_Carroll_1992 & & 824 & \\
\hline Stinchcombe_1965 & & ,821 & \\
\hline Hannan_1977 & & ,810 & \\
\hline Sorensen_Stuart_2000 & &, 810 & \\
\hline Freeman_et_al_1983 & & 806 & \\
\hline Amburgey_et_al_1993 & & ,806 & \\
\hline Carroll_1985 & & ,797 & \\
\hline Carroll_Hannan_1989 & & ,770 & \\
\hline Levinthal_1991 & & ,769 & \\
\hline Barnett_Sorenson_2002 & & ,761 & \\
\hline
\end{tabular}




\begin{tabular}{|l|l|l|l|}
\hline Podolny_1993 & &, 725 & \\
\hline Hannan_Freeman_1984 & &, 718 & \\
\hline Kelly_Amburgey_1991 & &, 715 & \\
\hline Meyer_Rowan_1977 & &, 688 & \\
\hline Barnett_Hansen_1996 & &, 900 \\
\hline Barnett_1997 & &, 743 \\
\hline Barnett_Carroll_1995 & &, 719 \\
\hline $\begin{array}{l}\text { Método de extração: Análise do Componente principal. } \\
\text { Método de rotação: Varimax com normalização de Kaiser. }\end{array}$ & \\
\hline
\end{tabular}

Fonte: Elaborada pelos autores (2017)

O primeiro cluster formado associa os trabalhos pelas seguintes linhas teóricas: Visão Baseada em Recursos (Barney, 1991; Dierickx \& Cool, 1989; Penrose \& Pitelies, 1959; Wernerfelt, 1984); Capabilities e Inovação (Leonard-Barton, 1992; Stuart \& Podolny, 1996; Brown \& Eisenhardt, 1997; Henderson \& Clark, 1990); e Aprendizagem Organizacional (Cohen \& Levinthal, 1990; Levinthal \& March, 1993; Levinthal, 1997; Levitt \& March, 1998; March, 1991). Por ser composto majoritariamente por estes temas, entende-se que esse fator representa muito da pesquisa que olha para dentro da organização, e que a estuda no nível micro (individual).

O segundo cluster formado é composto por linhas teóricas muito associadas à seleção natural das organizações. Aqui encontram-se trabalhos de ecologia organizacional e de estudos de nicho como um todo, sendo dada uma atenção especial à mortalidade organizacional. Desta forma, este fator representa um olhar voltado para o ambiente geral, em que se estuda o macro organizacional (populações).

O terceiro e menor cluster representa o estudo da teoria evolucionária das organizações, em que se discute especificamente como as organizações evoluem. Este fator é composto exclusivamente por trabalhos de Barnett e co-autores, sendo a lógica da Red Queen elemento de grande importância.
Portanto, da análise de co-citação, denota-se que os trabalhos que citam a Red Queen estão ancorados em dois principais clusters e em um terceiro mais específico. O primeiro, estuda a organização no nível micro (individual) e olha especificamente para dentro, considerando a aprendizagem organizacional um fator central e interligado aos recursos e às capabilities como forma de se gerar vantagem competitiva. Por outro lado, o segundo estuda as populações organizacionais, considerando o ambiente um fator determinístico e a seleção natural um processo ativo de evolução. Um terceiro cluster trata especificamente da teoria evolucionária das organizações, tendo a lógica da Red Queen como elemento de grande importância.

Logo abaixo, a Figura 2 ilustra o mapeamento de rede dos principais trabalhos co-citados. A rede foi feita com o uso do software UCINET. Os trabalhos identificados por um círculo compõem o fator 1 , denominado: Estudo das organizações no nível micro. $\mathrm{O}$ segundo fator é representado pelo quadrado, aqui denominado: Ecologia organizacional e estudos de nicho. O triângulo representa o terceiro fator, aqui denominado: Teoria evolucionária das organizações. $\mathrm{O}$ losango representa o grupo de trabalhos que foram excluídos da análise fatorial exploratória. 
Figura 2 - Mapeamento da rede dos trabalhos co-citados

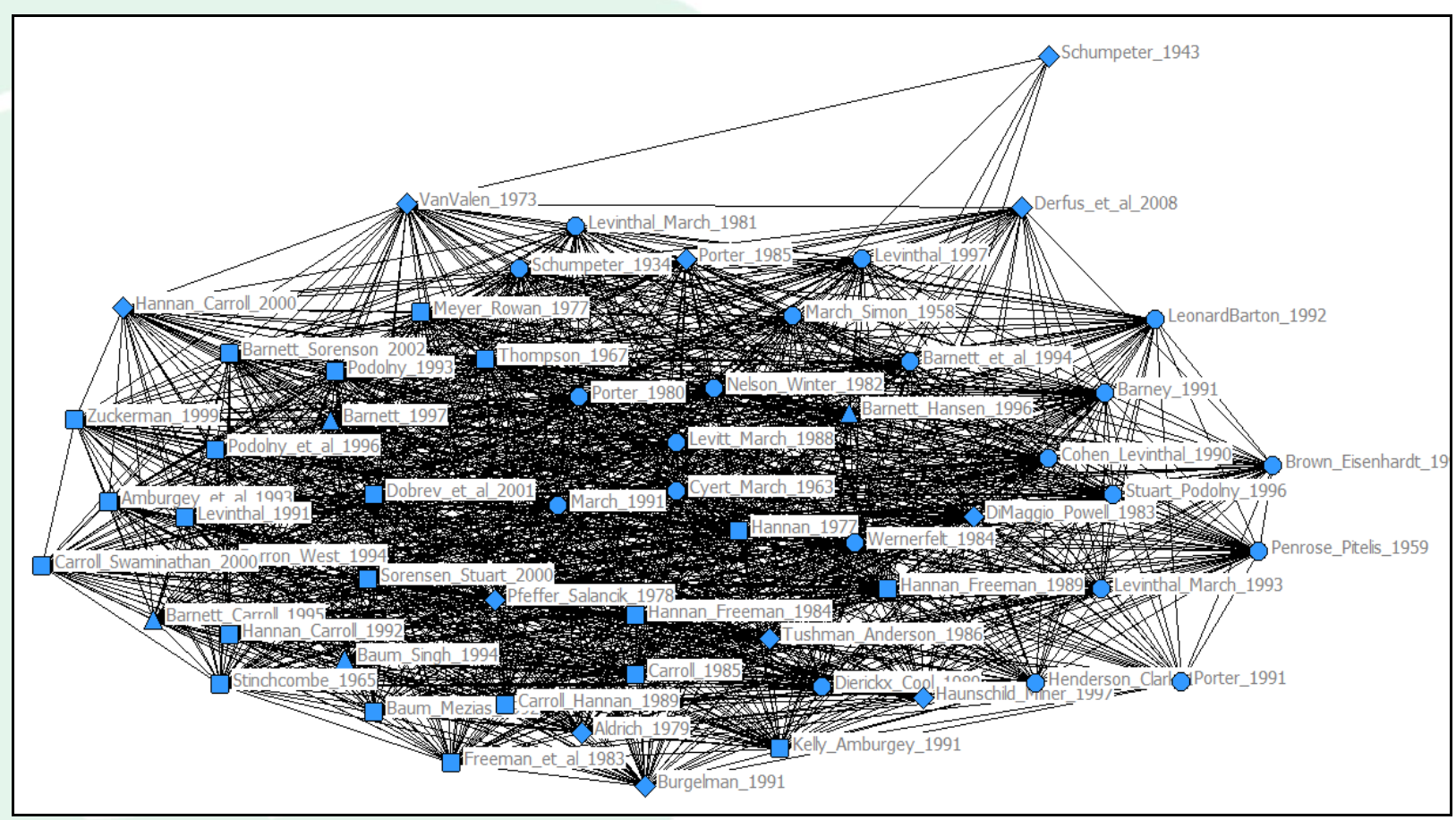

Fonte: Elaborada pelos autores (2017)

Os trabalhos identificados mais ao centro representam o grau de centralidade em relação aos outros trabalhos, servindo, portanto, de base para as demais pesquisas. A espessura das linhas representa a quantidade de vezes em que os trabalhos se conectam. Com base neste diagrama, nota-se que o trabalho de March (1991), que traz luz às diferenças entre exploration e exploitation dentro da aprendizagem organizacional, é o trabalho central para esta amostra de trabalhos. Os trabalhos encontrados no $3^{\circ}$ fator aparecem espalhados pelo diagrama, não apresentando uma homogeneidade tão forte quanto a análise fatorial exploratória propôs. Os fatores 1 e 2 parecem estar bem alinhados com os resultados fatoriais. Shumpeter (1943) e Van Valen (1973) parecem ter sidos antecedentes fortes das pesquisas encontradas nesta amostra, e, de forma similar, Derfus et al (2008) e Burgelman (1991) também parecem ter tido influência. The Red Queen in Organizational Evolution: Análise
de acoplamento bibliográfico (pareamento)

Para o pareamento, também houve o uso da análise fatorial exploratória. Seguindo os mesmos procedimentos da seção anterior, obteve-se um KMO de 0,935 , e o surgimento de 3 fatores explicando $71,30 \%$ da variância total da amostra. Foram analisados 88 trabalhos. A Tabela 6 sintetiza os 10 trabalhos com maiores cargas fatoriais associadas aos seus respectivos fatores. 
Tabela 6 - Síntese dos 10 artigos com maiores cargas fatoriais

\begin{tabular}{|c|c|c|c|c|c|c|}
\hline \multicolumn{7}{|c|}{ Matriz de componente rotativa ${ }^{a}$} \\
\hline Pos. & Artigo - Fator 1 & Carga & Artigo - Fator 2 & Carga & Artigo - Fator 3 & Carga \\
\hline 1 & Barnett_Pontikes_2004 &, 866 & Barkema_et_al_2002 &, 870 & Dobrev_et_al_2001 &, 844 \\
\hline 2 & Kim_Kuilman_2013 &, 832 & Farjoun_2002 &, 851 & Sorenson_2000 &, 840 \\
\hline 3 & Larsen_Lomi_1999 &, 830 & Dickson_et_al_1998 &, 842 & Sorenson_2000b &, 839 \\
\hline 4 & Gimeno_et_al_2006 &, 819 & Lado_et_al_2006 &, 832 & Zhou_Witteloostuijn_2010 &, 826 \\
\hline 5 & Mens_et_al_2014 &, 803 & Roberts_Amit_2003 &, 820 & Hannan_et_al_2003 &, 817 \\
\hline 6 & DSouza_et_al_2017 &, 800 & Teigland_Wasko_2003 &, 810 & Polos_et_al_2002 &, 804 \\
\hline 7 & Lin_Dang_2016 &, 800 & Tzabbar_2009 &, 803 & Hannan_et_al_1998 &, 804 \\
\hline 8 & Routley_et_al_2013 &, 793 & Aime_et_al_2010 &, 798 & Sorensen_Sorenson_2003 &, 803 \\
\hline 9 & Roos_Oliver_1999 &, 793 & Burgelman_Grove_2007 &, 798 & Bothner_et_al_2007 &, 799 \\
\hline 10 & Talay_Townsend_2015 &, 791 & Chiles_Choi_2000 &, 798 & Barnett_Sorenson_2002 &, 794 \\
\hline $\begin{array}{l}\text { Método de extração: Análise do Componente principal. } \\
\text { Método de rotação: Varimax com normalização de Kaiser. }\end{array}$ \\
\hline
\end{tabular}

Fonte: Elaborada pelos autores (2017)

Os trabalhos que compuseram o fator 1 discutiam aspectos relacionados ao mercado e à concorrência: histórico de competição entre organizações, inércia e mudança organizacional, ambiente dinâmico, relação entre consistência estratégica e desempenho organizacional; e natureza e duração da concorrência foram características importantes notadas neste fator. Diante de tais aspectos, nomeou-se esse fator de: Os impactos do ambiente e da concorrência na competição organizacional.

O fator 2 foi composto por trabalhos que discutiam majoritariamente novos modelos e processos de gerência e estratégia: modelos causais relacionados à estratégia, quadros que consideram a interação do mercado dinâmico, novos produtos e processos para determinados setores, conjunto de rotinas; e processos de estratégia foram algumas das características mais notadas neste fator. Diante de tais aspectos, nomeou-se esse fator de: Modelos e processos organizacionais e estratégicos.

O terceiro e último fator foi composto por trabalhos que discutiam a ecologia organizacional. Os termos mais encontrados neste fator foram: nicho organizacional, densidade organizacional, seleção organizacional, códigos sociais, e mortalidade organizacional. Diante das principais características deste fator, nomeou-se este fator de: Ecologia organizacional.

\section{CONSIDERAÇÕES FINAIS}

A importância do trabalho de Barnett orientado para a teoria da Red Queen parece se sustentar no tempo. Desde a publicação do artigo original de Barnett e Hansen (1996) os resultados obtidos apontam para a publicação contínua de artigos que referenciam aquela obra. Esse número de citações por ano se mantém ou experimenta um pequeno aumento após a publicação de TRQAO, em 2008. ;É importante notar que a análise de citações (bem como as demais análises bibliométricas realizadas) foi feita a partir da extração de referências indexadas na base ISI Web of Science, considerada de alto valor pela comunidade científica por cobrir somente as revistas internacionais ou regionais consideradas "top tier" (Torres-Salinas et al., 2014). Uma pesquisa a partir de outras bases de dados não tão seletivas possivelmente apontaria a publicação ainda maior de obras com citações à teoria da Red Queen. Merece destaque o fato de que mesmo no escopo restrito das publicações indexadas na base ISI Web of Science, entre as revistas que publicaram o maior número de artigos que fazem referência à teoria da Red Queen (conforme mostra a Tabela 2) estão algumas das publicações de mais elevado fator de impacto na Administração, o que atesta, além da mera manutenção de um número constante de referências ao longo dos anos, que a teoria se mantém relevante para os pesquisadores com a capacidade de produção da mais elevada qualidade nesse campo das Ciências Sociais.

Barnett e a Red Queen se fazem presentes em vários domínios da literatura. Neste estudo, foram pesquisados especificamente Organizational Evolution; Organizational Learning; e Organizational Ecology. Barnett aparece com mais expressividade nos estudos relacionados à ecologia organizacional, enquanto que a Red Queen é encontrada com mais força no campo da evolução organizacional. A Red Queen, na bibliometria representada pelo artigo "The Red Queen in Organizational Evolution” (1996), não demonstrou 
expressão no estudo da aprendizagem organizacional, assim como o autor (Barnett) também pareceu inexpressivo neste domínio.

A análise de co-citação sugere que os trabalhos que citam a Red Queen, estão alicerçados em dois grandes clusters, aqui denominados: 1) estudo das organizações no nível micro e prioritariamente interno; 2) ecologia organizacional e estudos de nicho. Um terceiro cluster aparece tratando especificamente da Red Queen e da teoria evolucionária. Essas três linhas teóricas ajudam a entender como os pesquisadores têm tratado temas como competição, fundação e mortalidade organizacional, e evolução das organizações, quando citam a Red Queen. O mapeamento dessa rede confirma a força dos 2 principais clusters; afirma o trabalho de March (1991) como central; e sugere a Red Queen e a teoria evolucionária como temas heterogêneos.

Por último, a análise de acoplamento bibliográfico (pareamento) contou com 88 trabalhos, que juntos geraram 3 fatores. Os 10 trabalhos com maiores cargas fatoriais de cada fator foram destacados e apresentados na tabela 6. Cada fator pode ser interpretado como um direcionamento das pesquisas que citam a Red Queen. O primeiro fator é composto por trabalhos que tratam dos impactos do ambiente e da concorrência na competição organizacional. O segundo, trata de modelos e processos organizacionais e estratégicos, dando ênfase a frameworks e à lógica estrutural. O último, discute a ecologia organizacional área de maior relevância para os trabalhos de Barnett.

\section{REFERÊNCIAS}

Aime, F., Johnson, S., Ridge, J., \& Hill, A. (2010). The routine may be stable but the advantage is not: competitive implications of key employee mobility. Strategic Management Journal, 31(1), 75-87.

Amburgey, T., Kelly, D., \& Barnett, W. (1993). Resetting the Clock: the dynamics of organizational change and failure. Administrative Science Quarterly, 38(1), 51-73.

Amburgey, T. L., \& Rao, H. (1996). Organizational ecology: past, present, and future directions. Academy of Management Journal, 39(5), 12651286

Bain, J. (1968). Industrial organization. New York: Wiley.

Barkema, H., Baum, J., \& Mannix, E. (2002). Management challenges in a new time. The Academy of Management Journal, 45(5), 916-930.

Barnett, W., \& Carroll, G. (1987). Competition and mutualism among early telephone companies. Administrative Science Quarterly, 32(3), 400-421.
Barnett, W. (1990). The organizational ecology of a technological system. Administrative Science Quarterly, 35(1), 31-60.

Barnett, W., \& Amburgey, T. (1990). Do larger organizations generate stronger competition?. In J. Singu (ed.). Organizational Evolution: New Directions. Beverly Hills: Sage.

Barnett, W., Greve, H., \& Park, D. (1994). An evolutionary model of organizational performance. Strategic Management Journal, 15(S1), 11-28.

Barnett, W., \& Carroll, G. (1995). Modeling Internal Organizational Change. Annual Review of Sociology, 21(1), 217-236.

Barnett, W. P., \& Hansen, M. T. (1996). The Red Queen in organizational evolution. Strategic Management Journal, 17(S1), 139-157.

Barnett, W. (1997). The dynamics of competitive intensity. Administrative Science Quarterly, 52(1), 128-160.

Barnett, W., \& Sorenson, O. (2002). The red queen in organizational creation and development. Industrial and Corporate Change, 11(2), 289-325.

Barnett, W., \& Pontikes, E. (2004). The red queen: history-dependent competition among organizations. Research in Organizational Behavior, 26(1), 351-371.

Barney, J. (1991). Firm resources and sustained competitive advantage. Journal of Management, 17(1), 99-120.

Baum, J., \& Mezias, S. (1992). Localized competition and organizational failure in the Manhattan Hotel Industry, 1898-1990. Administrative Science Quarterly, 37(4), 580-604.

Baum, J., \& Singh, J. (1994). Organizational niches and the dynamics of organizational mortality. American Journal of Sociology, 100(2), 346-380.

Baumol, W. J. (2004). Red-queen games: arms races, rule of law and market economies. Journal of Evolutionary Economics, 14(2): 237-247.

Barron, D., \& West, E. (1994). A time to grow and a time to die: growth and mortality of credit unions in New York city, 1914-1990. American Journal of Sociology, 100(2), 381-421.

Bar-Ilan, J. (2014). Citations to the "Introduction to informetrics" indexed by WOS, Scopus and Google Scholar. Scientometrics, 82(3), 495-506. 
Bothner, M., Kang, J., \& Stuart, T. (2007). Competitive crowding and risk taking in a tournament: evidence from NASCAR Racing. Administrative Science Quarterly, 62(2), 208-247.

Broadus, R. N. (1987). Towards a definition of "bibliometrics". Scientometrics, 12(5-6), 373-379.

Brown, S., \& Eisenhardt, K. (1997). Linking complexity theory and time-paced evolution in ralentlessly shifting organizations. Administrative Science Quarterly, 42(1), 1-34.

Burgelman, R. (1991). Intraorganizational ecology of strategy making and organizational adaptation: theory and field research. Organization Science, 2(3), 239-262.

Burgelman, R., \& Grove, A. (2007). Let chaos reign, then rein in chaos - repeatedly: managing strategic dynamics for corporate longevity. Strategic Management Journal, 28(1), 965-979.

Carroll, G. R. (1984). Organizational ecology. In R. H. Turner \& J. F. Short, Jr. (Eds.), Annual Review of Sociology,vol. 10, 71-93. Palo Alto, CA: Annual Reviews.

Carroll, G. (1985). Concentration and specialization: dynamics of nice width in populations of organizations. American Journal of Sociology, 90(6), 1262-1283.

Carroll, G., \& Hannan, M. (1989). Density delay in the evolution of organizational populations: a model and five empirical tests. Administrative Science Quarterly, 34(3), 411-430.

Carroll, G., \& Swaminathan, A. (2000). Why the microbrewery movement? organizational dynamics of resource partitioning in the U.S. Brewing Industry. American Journal of Sociology, 106(3), 715-762.

Carroll, G. R., \& Barnett, W. P. (2004). Organizational ecology: an introduction. Industrial and Corporate Change, 13(1), 1.

Carroll, L. (1992). Alice's Adventures in Wonderland and Through the Looking Glass. New York: Everyman's Library Children's Classics.

Chiles, T., \& Choi, T. (2000). Theorizing TQM: an austrian and evolutionary economics interpretation. Journal of Management Studies, 37(2), 186-212.

Cobo, M. J., López-Herrera, A. G., Herrera-Viedma, E., \& Herrera, F. (2011). An approach for detecting, quantifying, and visualizing the evolution of a research field: A practical application to the fuzzy sets theory field. Journal of Informetrics, 5(1), 146166.

Cohen, W., \& Levinthal, D. (1990). Absorptive capacity: a new perspective on learning and innovation. Administrative Science Quarterly, 35(1), 128-152.

Cyert, R. M., \& March, J. G. A. (1963). A behavioral theory of the firm. Englewood Cliffs, NJ: PrenticeHall.

Derfus, P. J, Maggitti, P. G., Grimn, C. M., \& Smith, K. G. (2008). The Red Queen effect: competitive actions and firm performance. The Academy of Management Journal, 51(1), 61-80.

Dickson, P., Farris, P., \& Verbeke, W. (1998). Dynamic strategic thinking. Journal of the Academy of Marketing Science, 29(3), 216-237.

Dierickx, I., \& Cool, K. Asset stock accumulation and sustainability of competitive advantage. Management Science, 35(12), 1504-1511.

DiMaggio, P., \& Powell, W. (1983). The iron cage revisited: institutional isomorphism and collective rationality in organizational fields. American Sociological Review, 48(2), 147-160.

Dobrev, S., Kim, T., \& Hannan, M. (2001). Dynamics of niche width and resource partitioning. American Journal of Sociology, 106(5), 1299-1337.

D'Souza, E., Sigdyal, P., \& Struckell, E. (2017). Relative ambidexterity: a measure and a versatile framework. The Academy of Management Perspectives, 31(2), 124-136.

Dyer, J. H., \& Singh, H. (1998). The relational view: cooperative strategy and sources of interorganisational competitive advantage. Academy of Management Review, 23(4), 660-679.

Eisenhardt, K. (1989). Building theories from case study research. Academy of Management Review, 14(4), 532-550.

Farjoun, M. (2002). Towards an organic perspective on strategy. Strategic Management Journal, 23(7), 561-594.

Freeman, J., Carroll, G., \& Hannan, M. (1983). The liability of newness: age dependence in organizational death rates. American Sociological Review, 48(5), 692-710. 
Garfield, E. (1979). Is citation analysis a legitimate evaluation tool?. Scientometrics, 1(4), 359-375.

Gimeno, J., Chen, M., \& Bae, J. (2006). Dynamics of competitive repositioning: a multidimensional approach. In J. Baum, S. Dobrev, \& A. Witteloostuijn (ed.). Ecology and Strategy (Advances in Strategic Management, Volume 23), Esmerald Group Publishing Limited, pp. 399-441.

Glazebrook, J. F., \& Wallace, R. (2009). Small worlds and Red Queens in the global workspace: an information-theoretic approach. Cognitive Systems Research, 10(4), 333-365.

Granovetter, M. (1985). Economic action and social structure: the problem of embeddedness. American Journal of Sociology, 91(3), 481-510.

Hannan, M. T., \& Freeman, J. (1977). The population ecology of organizations. American Journal of Sociology, 82(5), 929-964.

Hannan, M., \& Freeman, J. (1984). Structural inertia and organizational change. American Sociological Review, 49(2), 149-164.

Hannan, M., \& Freeman, J. (1989). Organizational Ecology. Cambridge, MA: Harvard University Press.

Hannan, M., \& Carroll, G. (1992). Dynamics of Organizational Populations: Density, Legitimation, and Competition. Oxford: Oxford University Press.

Hannan, M., \& Carroll, G. (1999). The Demography of corporation and industries. Princeton, NJ: Princeton University Press.

Hannan, M., Carroll, G., Dobrev, S., \& Han, J. (1998). Organizational mortality in european and american automobile industries. Part I: revisiting the effects of age and size. European Sociological Review, 14(3), 279-302.

Hannan, M., Pólos, L., \& Carroll, G. (2003). Cascading organizational change. Organization Science, 14(5), 463-482.

Haunschild, P., \& Miner, A. (1997). Modes of interorganizational imitation: the effects of outcome salience and uncertainty. Administrative Science Quarterly, 42(3), 472-500.

Henderson, R., \& Clark, K. (1990). The reconfiguration of existing product technologies and the failure of established firms. Admnistrative Science Quarterly, 35(1), 9-30.
Kelly, D., \& Amburgey, T. (1991). Organizational inertia and momentum: a dynamic model of strategic change. The Academy of Management Journal, 34(3), 591-612.

Kim, T., \& Kuilman, J. (2013). The demography of resources. Journal of Management Studies, 50(7), 1155-1184.

Lado, A., Boyd, N., Wright, P., \& Kroll, M. (2006). Paradox and theorizing within the resource-based view. Academy of Management Review, 31(1), 115131.

Larsen, E., \& Lomi, A. (1999). Resetting the clock: a feedback approach to the dynamics of organisational inertia, survival and change. Journal of the Operational Research Society, 50(4), 406421.

Leonard-Barton, D. (1992). Core capabilities and core rigidities: a paradox in managing new product development. Strategic Mangement Journal, 13(S1), 111-125.

Levitt, B., \& March, J. (1988). Organizational learning. In W. R. Scott \& J. Blake (Eds.), Annual Review of Sociology, vol. 14, 319-340. Palo Alto, CA: Annual Reviews.

Levinthal, D., \& March, J. (1981). A model of adaptive organizational search. Journal of Economic Behavior and Organization, 2(4), 307-333.

Levinthal, D. (1991). Random walks and organizational mortality. Administrative Science Quarterly, 36(3), 397-420.

Levinthal, D., \& March, J. (1993). The myopia of learning. Strategic Management Journal, 14(S2), 95-112.

Levinthal, D. (1997). Adaptation on rugged landscapes. Management Science, 43(7), 934-950.

Lin, C., \& Dang, V. (2016). Untangling the relationship between strategic consistency and organizational performance: an empirical analysis of moderator variables. Journal of Management \& Organization, 23(4), 483-503.

March, J. (1991). Exploration and exploitation in organizational learning. Organization Science, 2(1), 71-87.

March, J., \& Simon, H. (1958). Organizations. New York: Wiley Blackwell.

Marrow, P., Law, R., \& Cannings, C. (1992). The coevolution of predator prey interactions - ESSS 
and Red Queen dynamics. Proceedings of the Royal Society B-Biological Sciences, 250(1328), 133-141

McCain, K. W. (1990). Mapping authors in intellectual space: a technical overview. Journal of the American Society for Information Science, 41(6), 433-443..

Mens, G., Hannan, M., \& Pólos, L. (2014). Organizational obsolescence, drifting tastes, and age dependence in organizational life chances. Organization Science, 26(2), 550-570.

Meyer, J., \& Rowan, B. (1977). Institutionalized organizations: formal structure as mith and ceremony. American Journal of Sociology, 83(2), 340-363.

Nelson, R. R., \& Winter, S. G. (1982). An evolutionary theory of economic change. Cambridge, MA: Belknap.

Penrose, E. (1959). The theory of the growth of the firm. Oxford: Oxford University Press.

Podolny, J. (1993). A status-based model of market competition. American Journal of Sociology, 98(4), 829-872.

Podolny, J., Stuart, T., \& Hannan, M. (1996). networks, knowledge, and niches; competition in the worldwide semiconductor industry, 1984-1991. American Journal of Sociology, 102(3), 659-689.

Pólos, L., Hannan, M., \& Carroll, G. (2002). Foundations of a theory of social forms. Industrial and Corporate Change, 11(1), 85-115.

Porter, M. (1980). Competitive Strategy: techniques for analyzing industries and competitors. New York: Free Press.

Porter, M. (1991). Towards a dynamic theory of strategy. Strategic Management Journal, 12(S2), 95-117.

Ramos-Rodríguez, A. R., \& Ruíz-Navarro, J. R. (2004). Changes in the intellectual structure of strategic management research: a bibliometric study of the Strategic Management Journal, 1980-2000. Strategic Management Journal, 25(10), 981-1004.

Roberts, P., \& Amit, R. (2003). The dynamics of innovative activity and competitive advantage: the case of australian retail banking, 1981 to 1995. Organization Science, 14(2), 107-122.
Roos, J., \& Oliver, D. (1999). From fitness landscapes to knowledge landscapes. Systemic Practice and Action Research, 12(3), 279-293.

Routley, M., Phaal, R., Athanassopoulou, N., \& Probert, D. (2013). Mapping Experience in organizations: a learning process for strategic technology planning. Engineering Management Journal, 25(1), 35-47.

Schumpeter, J. (1934). The theory of economic development: an inquiry into profits, capital, credit, interest, and the business cycle. London: Transaction Publishers.

Schumpeter, J. (1942). Capitalism, Socialism, and Democracy. London: George Allen \& Unwin.

Singh, J. V., \& Lumsden, C. J. (1990). In W. R. Scott, \& J. Blake (Eds.). Theory and research in organizational ecology. Annual Review of Sociology, vol. 16, 161-195. Palo Alto, CA: Annual Reviews.

Small, H. (1973). Co-citation in the scientific literature: a new measure of the relationship between two documents. Journal of the American Society for information Science, 24(4), 265-269.

Sorensen, J., \& Stuart, T. (2000). Aging, obsolescence, and organizational innovation. Administrative Science Quarterly, 45(1), 81-112.

Sorensen, J., \& Sorenson, L. (2003). From conception to birth: opportunity perception and resource mobilization in entrepreneurship. In J. Baum, \& O. Sorenson (ed,). Geography and Strategy (Advances in Strategic Management, Volume 20). Emerald Group Publishing Limited, 89-117.

Sorenson, O. (2000). Letting the market work for you: an evolutionary perspective on product strategy. Strategic Management Journal, 21(5), 577-592.

Sorenson, O. (2000). The effect of population-level learning on market entry: the american automobile industry. Social Science Research, 29(3), 307-326.

Stinchcombe, A. (1965). Social structure and organizations. Advances in Strategic Management, 17(1), 229-259.

Stuart, T., \& Podolny, J. (1996). Local search and the evolution of technological capabilities. Strategic Management Journal, 17(S1), 21-38.

Su, H. C., Linderman, K., Schroeder, R. G., \& Van de ven, A. H. (2014). A comparative case study of sustaining quality as a competitive advantage. 
Journal of Operations Management, 32(7-8), 429445.

Swaminathan, A. (2009). The Red Queen among organizations: how competitiveness evolves. Administrative Science Quarterly, 54(4), 689-691.

Talay, M., \& Townsend, J. (2015). Do or die: competitive effects and red queen dynamics in the product survival race. Industrial and Corporate Change, 24(3), 721-738Teece, D., Pisano, G., \& Shuen, A. (1997). Dynamic capabilities and strategic management. Strategic Management Journal, 18(7). 509-533.

Teigland, R., \& Wasko, M. (2003). Integrating knowledge through information trading: examining the relationship between boundary spanning communication and individual performance. Decision Sciences, 34(2), 261-286.

Torres-Salinas, D., Robinson-Garcia, N., Campanario, J. M., \& López-Cózar, E. D. (2014). Coverage, field specialisation and the impact of scientific publishers indexed in the Book Citation Index. Online Information Review, 38(1), 24-42.
Tzabbar, D. (2009). When does scientist recruitment affect technological repositioning?. The Academy of Management Journal, 52(5), 873-896.

van Valen, L. (1973). A new evolutionary law. Evolutionary Theory, 1, 1-30.

Wernerfelt, B. (1984). A resource-based view of the firm. Strategic Management Journal, 5(2), 171180.

Zhow, C., \& Witteloostuijn, A. (2010). Institutional constraints and ecological processes: evolution of foreign-invested enterprises in the chinese construction industry, 1993-2006. Journal of International Business Studies, 41(3), 539-556.

Zuckerman, E. (1999). The categorical imperative: securities analysts and the illegitimacy discount. American Journal of Sociology, 104(5), 1398-1438.

Zupic, I., Cater, T. (2015). Bibliometric methods in management and organization. Organizational Research Methods, 18(3), 429-472. 